\title{
Reflexões sobre o ensino da língua escrita em tempos de ampliação da escolarização obrigatória
}

\author{
Reflections about written language teaching in times of extending of the obligatory schooling \\ Reflexiones sobre la enseñanza del lenguaje escrito en tiempos de expansión escolar obligatoria
}

\begin{abstract}
Maria Angélica Olivo Francisco Lucas - Universidade Estadual de Maringá - UEM | Programa de PósGraduação em Educação (PPE) | Maringá | PR | Brasil. E-mail: mangelicaofl@ibest.com.br (DorciD
\end{abstract}

Heloisa Toshie Irie Saito - Universidade Estadual de Maringá - UEM | Departamento de Teoria e Prática da Educação (DTP) e do Programa de Pós-graduação em Educação (PPE) Maringá | PR | Brasil. E-mail: heloisairie@gmail.com DORCID

Lucinéia Maria Lazaretti - Universidade Estadual do Paraná -UNESPAR | Colegiado de Pedagogia | Paranavaí | PR | Brasil. E-mail: lucylazaretti@gmail.com (1) ORCID

Resumo: No contexto de progressiva democratização da escolarização obrigatória brasileira, envolvendo a ampliação do ensino fundamental e a reorganização da educação infantil, como justificar a importância da aprendizagem da escrita para o desenvolvimento infantil e orientar a implementação de práticas pedagógicas que abrangem esse tipo de linguagem? Em busca de respostas a essa questão, objetivamos com este artigo refletir sobre o ensino e a aprendizagem da língua escrita no universo da educação infantil, de maneira a abordar os processos de letramento e de alfabetização. Para isso, realizamos um estudo bibliográfico acompanhado de análise documental, cujos resultados são expostos em três partes: apresentamos alguns princípios de duas importantes teorias que explicam o processo de aprendizagem da leitura e da escrita - construtivista e histórico-cultural; conceituamos os processos de alfabetização e de letramento, defendendo-os como indissociáveis e interdependentes; refletimos sobre a implementação intencional de práticas pedagógicas de alfabetização e de letramento na educação infantil, atentas às especificidades das crianças desse nível de ensino a partir da análise de algumas orientações teórico-metodológicas presentes em dois documentos oficiais, um de âmbito estadual e outro de âmbito nacional.

Palavras-chave: Língua escrita. Educação infantil. Escolarização obrigatória.

Abstract: In the context of progressive democratization of brazillian education, which envolves the expansion of high school and the child education rearrangement, we ask ourselves: in a context of amplified obligatory schooling, how to justify that learning to write as important for child development, as well as guiding the use of pedagogical practices that cover this kind of language? Seeking answers for that question, we aim thinking over the teaching and learning of the written language in the universe of child education, abording the literacy process. For such objective, we carry out a bibliographical study accompanied by documentary analysis, whose results are exposed in three parts: we showed some of the principles of two different theories that explain the process of reading and writing - constructivist and historical-cultural; we've conceptualize the literacy process in it's pragmatic and literal meanings, defending that they're both indissociable and interdependants; we've debated over the intentional implementation of pedagogical practices of literacy in child education, attentive to the specificities of children of this level of education from the analysis of some theoretical and methodological orientations present in two official documents, one statewide and the other scope national

Keywords: Written language. Child education. Obligatory education.

Resumen: Considerando el contexto de la democratización progresiva de la escolarización obligatoria en Brasil, que implica la expansión de la escuela primaria y la reorganización de la educación de la primera infancia, ¿cómo podemos justificar la importancia del aprendizaje de la escritura para el desarrollo infantil y guiar la implementación de prácticas pedagógicas que cubren este tipo de lenguaje? En busca de respuestas a esta pregunta, este artículo tiene como objetivo reflexionar sobre la enseñanza y el aprendizaje del lenguaje escrito en el universo de la educación de la primera infancia, a fin de abordar los procesos de alfabetización y literacidad. Para esto, realizamos un estudio bibliográfico acompañado de un análisis documental, cuyos resultados se presentan en tres partes: presentaremos algunos principios de dos teorías importantes que explican el proceso de aprendizaje de la lectura y la escritura: constructivista e histórico-cultural; conceptualizaremos los procesos de alfabetización y literacidad, defendiéndolos como inseparables e interdependientes; Reflexionamos sobre la implementación intencional de prácticas pedagógicas de alfabetización y literacidad en la educación de la primera infancia, prestando atención a las especificidades de los niños de este nivel educativo a partir del análisis de algunas orientaciones teórico-metodológicas presentes en dos documentos oficiales, uno de ámbito estatal y otro de ámbito nacional.

Palabras clave: Lenguaje escrito. Educación Infantil. Escolarización obligatoria.

- Recebido em 20 de dezembro de 2018 • Aprovado em 11 de julho de 2019 • e-ISSN: 2177-5796

DOI: http://dx.doi.org/10.22483/2177-5796.2019v21n3p901-919

Copyright @ 2019. Conteúdo de acesso aberto, distribuído sob os termos da Licença Internaonal da CreativeCommons - CC BY-NC-SA Atribuição Não Comercial (https://br.creativecommons.org/licencas/) - Permite distribuição e reprodução, desde que atribuam os devido créditos à publicação, ao autor(es) e que licenciem as novas criações sob termos idênticos. 
LUCAS, Maria Angélica Olivo Francisco; SAITO, Heloisa Toshie Irie; LAZARETTI, Lucinéia Maria. Reflexões sobre o ensino da língua escrita em tempos de ampliação da escolarização obrigatória.

\section{Contextualizando o tema}

Após a década de 1980, análises e críticas acerca dos problemas educacionais brasileiros, tanto os relacionados à educação das crianças pequenas quanto os ligados ao fracasso de nossas escolas ao ensinarem o mecanismo da leitura e da escrita e o uso competente de tais habilidades ganharam destaque no universo acadêmico, nas instituições educativas e no dia a dia das pessoas. O empenho de pesquisadores, de estudiosos, de professores e de demais profissionais da educação, estava, naquela época, centrado na compreensão de tais problemas, a fim de pensar soluções e alternativas que objetivassem democratizar a educação (LUCAS, 2009).

Das discussões iniciadas no período mencionado, as quais perduram até os dias atuais, sobressaem as que objetivam definir uma finalidade pedagógica para a educação infantil, propondo a superação das finalidades assistencialistas que marcaram, desde o princípio, esse primeiro nível da educação básica. Uma retrospectiva dos distintos papéis que a educação infantil brasileira exerceu no decorrer das últimas quatro décadas demonstra que a sua trajetória em busca de uma função pedagógica é rica em particularidades (LUCAS; MACHADO, 2012). Avanços e retrocessos podem ser observados, principalmente quando são considerados os determinantes econômicos, a conjuntura política e a correlação de forças presentes na sociedade nos períodos em que os principais documentos legais que dizem respeito à educação infantil foram organizados, debatidos, aprovados e implementados.

Foi assim no processo de elaboração do texto constitucional promulgado em 1988 que reconheceu as crianças como cidadãs ao conferir-lhes, entre outros aspectos, o direito à educação em creches e em pré-escolas, determinando que sua garantia é dever do Estado; do Estatuto da Criança e do Adolescente (ECA), em 1990, que reforçou o compromisso do Estado com a educação das crianças de até 6 anos (BRASIL, 1990); da Política Nacional de Educação Infantil, em 1994, a qual definiu o cuidar e o educar como duas funções complementares e indissociáveis; da Lei de Diretrizes e Bases da Educação Nacional (LDB 9.394/1996) que incorporou a educação infantil à educação básica (BRASIL, 1996); do Referencial Curricular Nacional para a Educação Infantil (RCNEI), em 1998 (BRASIL, 1998), e das Diretrizes Curriculares Nacionais para a Educação Infantil (DCNEI), em 1999 (BRASIL, 1999), que ocuparam-se de aspectos pedagógicos da educação infantil, apesar de resultarem de caminhos distintos, executados por instâncias diferentes - o primeiro, pela Coordenação Geral de Educação Infantil (Coedi-MEC) e o segundo, pelo Conselho Nacional de Educação (CNE). 
LUCAS, Maria Angélica Olivo Francisco; SAITO, Heloisa Toshie Irie; LAZARETTI, Lucinéia Maria. Reflexões sobre o ensino da língua escrita em tempos de ampliação da escolarização obrigatória.

No contexto das discussões que envolveram a elaboração, a aprovação e a implantação dos documentos mencionados, os quais, apesar dos avanços e dos retrocessos, buscam incessantemente reafirmar uma função pedagógica para a educação infantil que garanta o desenvolvimento físico, cognitivo e emocional das crianças, ou seja, o seu desenvolvimento pleno, os debates sobre a relevância de um trabalho que englobe os processos de ensino e de aprendizagem da língua escrita na educação infantil ganharam volume. Contudo, apesar de a ciência trazer elementos esclarecedores, a relação entre educação infantil e ensino da língua escrita mostrou-se, historicamente, conturbada e polêmica.

Tal polêmica ganhou novos contornos no início do novo milênio com as seguintes alterações realizadas na LDB: a Lei n. ${ }^{\circ} 11.114$ (BRASIL, 2005) modificou a idade de matrícula das crianças no ensino fundamental, as quais poderiam nele ingressar aos 6 anos de idade (completos ou a completar); a Lei n. ${ }^{\circ} 11.274$ (BRASIL, 2006) ampliou o tempo de duração do ensino fundamental para 9 anos; a Lei n. ${ }^{\circ} 12.796$ - a mais significativa (BRASIL, 2013) tornou obrigatória a matrícula de crianças com 4 e 5 anos de idade em préescolas (CZYZEWSKI; LUCAS, 2013).

Concomitantemente às preocupações iniciais referentes à idade de ingresso no ensino fundamental e à obrigatoriedade da pré-escola, muitas foram as dúvidas em relação ao encaminhamento da prática pedagógica, a qual se tornou alvo de questionamentos de profissionais que atuam nas duas instâncias. Nesse quadro de incertezas, o Ministério da Educação (MEC) não ficou inerte: publicou documentos para orientar as instituições educativas dos dois níveis de ensino e promoveu programas de formação continuada. Tais iniciativas, contudo, não foram suficientes para orientar os profissionais que trabalham com crianças pequenas em relação à implementação de práticas pedagógicas que visem à aprendizagem da língua escrita. Duas situações corriqueiras observadas em centros de educação infantil comprovam a assertiva anterior: trata-se da implementação de práticas pedagógicas que ou priorizam o ensino do código escrito desde a mais tenra idade, muitas vezes em detrimento de outros aspectos que envolvem o trabalho com a linguagem nesse nível de ensino, ou excluem totalmente a escrita das ações pedagógicas, realizando uma espécie de assepsia dessa linguagem em ambientes coletivos de educação para crianças pequenas (COLELLO; LUCAS, 2018). Nos dois casos, são desconsiderados tanto a aprendizagem e o desenvolvimento infantil quanto o processo de apropriação da língua escrita, abarcando os processos de alfabetização e de letramento.

É nesse contexto de progressiva democratização da educação brasileira, que envolve a 
LUCAS, Maria Angélica Olivo Francisco; SAITO, Heloisa Toshie Irie; LAZARETTI, Lucinéia Maria. Reflexões sobre o ensino da língua escrita em tempos de ampliação da escolarização obrigatória.

ampliação do ensino fundamental, a reorganização da educação infantil e o fortalecimento da formação continuada de professores, que localizamos a necessidade de revisitar um tema já discutido amplamente, porém em um outro contexto e em condições diferenciadas das atuais. Por isso, perguntamo-nos o seguinte: como justificar, em um contexto de escolarização obrigatória ampliada, a importância da aprendizagem da escrita para o desenvolvimento infantil e orientar a implementação de práticas pedagógicas que envolvem esse tipo de linguagem?

Afirmamos que a discussão sobre o ensino e a aprendizagem da língua escrita na educação infantil exige cautela, pois as reflexões que apresentamos e as práticas pedagógicas que indicamos precisam atender às especificidades das crianças desse nível de ensino, ou seja, devem ter como características a ludicidade, a aproximação com a linguagem oral, a função social da escrita e também a vivência com a criança, sempre considerando as características da faixa etária a ser trabalhada. Em outras palavras, defendemos uma aprendizagem da língua escrita que permita à criança expressar-se, comunicar-se e interagir com o mundo que a rodeia, podendo participar dele de modo autônomo e ativo.

A partir da retrospectiva, ainda que breve, da história da educação infantil brasileira em direção à definição de uma função pedagógica e da defesa dos aspectos anteriormente mencionados, nosso objetivo, com este artigo, é refletir sobre o ensino e a aprendizagem da língua escrita no universo da educação infantil, de maneira a abordar os processos de letramento e de alfabetização. Trata-se de um estudo bibliográfico acompanhado de análise documental, cujos resultados, serão apresentados em em três momentos. Inicialmente, discutimos alguns princípios de duas importantes teorias que explicam o processo de aprendizagem da leitura e da escrita, apresentando as contribuições de Ferreiro e Teberosky (1985) por meio da psicogênese da língua escrita, e as contribuições de Vygotski (2000) e de Luria (2006) com base em princípios da Teoria Histórico-Cultural (THC). Em um segundo momento, conceituamos os processos de alfabetização e de letramento, defendendo-os como indissociáveis e interdependentes mediante estudos realizados por Soares (1998, 2004a, 2004b). Por fim, para pensarmos práticas pedagógicas voltadas para a aprendizagem da escrita, destacamos algumas orientações teórico-metodológicas que abarcam os processos de alfabetização e de letramento presentes em dois documentos oficiais, um de âmbito estadual Orientações pedagógicas da educação infantil: estudos e reflexões para a organização do trabalho pedagógico (PARANÁ, 2015) e outro de âmbito nacional - Leitura e escrita na educação infantil (BRASIL, 2016). 
LUCAS, Maria Angélica Olivo Francisco; SAITO, Heloisa Toshie Irie; LAZARETTI, Lucinéia Maria. Reflexões sobre o ensino da língua escrita em tempos de ampliação da escolarização obrigatória.

\section{Aprendizagem da língua escrita}

A aprendizagem da língua escrita foi objeto de estudo de pesquisadores de diferentes correntes teóricas. Neste artigo, ocupamo-nos das contribuições de Ferreiro e colaboradores, com a psicogênese da língua escrita, e de estudos de Vygotsky (2000) e de Luria (2006), cuja base teórica é a THC. Não pretendemos fazer aproximações, tampouco estabelecer relações de completude entre tais correntes teóricas; apenas reconhecemos que ambas são resultados de pesquisas em que a criança é vista como sujeito ativo que elabora conceitos e que são estudos que lançam luz sobre os processos de ensino e de aprendizagem da língua escrita.

\subsection{Principais contribuições da perspectiva construtivista}

Emília Ferreiro, juntamente com Ana Teberosky e com a colaboração de outros pesquisadores, desenvolveu investigações a respeito da aprendizagem da escrita pela criança. Ferreiro e Teberosky (1985) demonstraram como as crianças pensam a escrita, evidenciando o caminho por elas percorrido para compreenderem as características, o valor e a função dessa forma de linguagem, bem como destacando as hipóteses por elas elaboradas em seu percurso de aprendizagem.

Elas criticaram os chamados métodos tradicionais de alfabetização, pelo fato de eles explicarem a aprendizagem da escrita tendo como modelo a forma como a criança se apropria da linguagem oral. Nessa lógica, a progressão iniciava-se com as vogais, seguidas de combinações de consoantes labiais com vogais (ba, pa), depois formando pequenas palavras com duplicação de sílabas (Lalá, Mimi), pequenas orações e assim sucessivamente. Como decorrência desse modelo, a escrita alfabética era concebida como uma transcrição fonética da língua. Essa concepção de língua como codificação embasa os métodos sintéticos e analíticos de alfabetização até os dias atuais, mesmo que "modernizados".

Azenha (2006) destaca duas contribuições expressivas da investigação desenvolvida por Ferreiro e Teberosky (1985). A primeira foi evidenciar o papel ativo do sujeito na relação com o objeto de conhecimento, ultrapassando, assim, a visão empirista subjacente aos métodos tradicionais de alfabetização, os quais concebem a leitura e a escrita como objetos exclusivos do ambiente escolar. A segunda foi evidenciar que a criança percorre uma trajetória com hipóteses próprias em direção à escrita formal cujo princípio ocorre antes de ela frequentar a escola, desmistificando a ideia de que ela parte do grau zero de aprendizagem da escrita (BARBOSA, 1994). Aliás, foi muito impactante a afirmação de que a criança, ao 
LUCAS, Maria Angélica Olivo Francisco; SAITO, Heloisa Toshie Irie; LAZARETTI, Lucinéia Maria. Reflexões sobre o ensino da língua escrita em tempos de ampliação da escolarização obrigatória.

ingressar no ensino fundamental, quando, geralmente, começa a ocorrer o ensino sistemático da leitura e da escrita, já possui grande competência linguística, normalmente desconsidera pela escola. Nas palavras das autoras: "Atualmente, sabemos que a criança que chega à escola tem um notável conhecimento de sua língua materna, um saber linguístico que utiliza 'sem saber' (inconscientemente) nos seus atos de comunicação cotidianos" (FERREIRO; TEBEROSKY, 1985, p. 24).

O modo de compreender como as crianças aprendem a ler e a escrever que norteou as investigações realizadas por Ferreiro, Teberosky e colaboradores estava balizado por três princípios. Eles são os seguintes:
a) a leitura não é decodificação de grafia em sons;
b) a escrita não é cópia de modelos;
c) os progressos na aprendizagem da leitura e da escrita não podem ser vistos como avanços na decifração ou na exatidão da cópia (LUCAS, 2009, p. 95).

Com base nesses três princípios, Ferreiro e Teberosky (1985) interpretaram as produções espontâneas de escrita das crianças (aquelas que ela escreve tal como acredita que certa palavra deve ser escrita, não resultando de cópia), ultrapassando a observação dos aspectos gráficos (qualidade do traço, distribuição espacial das formas traçadas no papel e orientação da escrita - da direita para a esquerda e de cima para baixo, entre outros), ou seja, considerando e refletindo acerca de seus aspectos construtivos, isto é, do que a criança quis representar e quais os meios por ela utilizados para diferenciar suas representações.

Por meio da análise cuidadosa dessas produções espontâneas de escritas, as autoras verificaram que nelas havia uma linha de evolução regular, semelhante em diferentes idiomas, ambientes culturais e situações, na qual identificaram três grandes períodos: distinção entre o modo de representação icônico e o não-icônico; construção de formas diferenciadas de escrita; fonetização da escrita. Em cada período, há subdivisões decorrentes das hipóteses que as crianças elaboram a respeito da leitura e da escrita. Pertencem ao terceiro período, as hipóteses mais conhecidas que correspondem aos níveis pré-silábico (sem correspondência grafo-fônica); silábico (início da compreensão da correspondência grafo-fônica, mas no nível da sílaba); alfabético (com correspondência grafo-fônica, mesmo havendo alterações ortográficas).

Não comportam, neste artigo, a descrição e a exemplificação de cada um desses períodos e níveis, inclusive porque já foram exaustivamente difundidos nos últimos 30 anos. Destacamos, contudo, algumas orientações teórico-metodológicas, tendo em vista a 
LUCAS, Maria Angélica Olivo Francisco; SAITO, Heloisa Toshie Irie; LAZARETTI, Lucinéia Maria. Reflexões sobre o ensino da língua escrita em tempos de ampliação da escolarização obrigatória.

implementação de práticas pedagógicas alfabetizadoras, depreendidas por Azenha (2006) da análise das pesquisas de Ferreiro e Teberosky (1985):

a) associação entre letras e sons: as crianças, em suas primeiras produções escritas, não supõem que exista relação entre letras e sons. Por isso, esse não pode ser o ponto de partida como propõem os métodos tradicionais de alfabetização, pois tal aprendizagem pressupõe o desenvolvimento da capacidade de representar a realidade por meio de símbolos;

b) erro construtivo: quando se reconhece que a criança elabora diferentes hipóteses a respeito da escrita, muda-se a forma de se conceber os erros que cometem em suas produções. Eles passam a ser vistos como necessários à aprendizagem e indicativos do caráter construtivo do conhecimento;

c) pré-requisitos para a alfabetização: além dos aspectos perceptuais e motores, há que se considerar os aspectos conceituais da escrita;

d) ler para as crianças: a leitura de textos diversos oportuniza à criança a interação com características da escrita e indica-lhe algumas de suas funções sociais;

e) registros escritos: histórias ou situações cotidianas narradas pelas crianças podem ser registradas pelo professor para que elas percebam que as ideias podem ser materializadas no papel e que existe relação entre a fala e a escrita;

f) nome próprio: a apropriação da forma escrita do nome próprio, além de ser um conteúdo significativo para a criança, oferece um rico material de confronto entre a escrita espontânea e a convencional;

g) escrita de textos: confeccionar listas de palavras, escrever cartas, bilhetes e registrar letras de canções são situações que oportunizam o contato com a escrita e a leitura e favorecem a aprendizagem de seus usos sociais;

h) funções sociais da escrita: Ferreiro e Teberosky (1985) demonstraram quão importante é para a alfabetização o trabalho com a leitura e com a escrita em situações nas quais são preservados seus usos sociais, diferentemente dos métodos tradicionais, que a concebem como um recurso meramente escolar, sem função social.

Por tudo isso e pela consistência teórica de suas investigações, autores como Weisz (1999), Azenha (2006), Mello (2007), dentre outros, consideram que os estudos de Ferreiro, de Teberosky e de colaboradores constituem uma revolução conceitual no campo da alfabetização.

\footnotetext{
Por romper com as concepções tradicionais de alfabetização; por conceber a língua escrita como um sistema de representação, resultado do esforço coletivo da humanidade e não apenas como um código de transcrição de unidades sonoras; por considerar a língua escrita como um objeto cultural e não meramente escolar; por conceber a aprendizagem dessa linguagem como um processo conceitual e não como aquisição de uma técnica; por ver a criança como um sujeito cognoscente, ativo e com competência lingüística, que constrói seu conhecimento na interação com o objeto de conhecimento e de acordo com uma seqüência ordenada; por ter abandonado a visão adultocêntrica do processo e a idéia segundo a qual é o método de ensino que alfabetiza sendo o professor o único informante autorizado; por tudo isso, as conclusões resultantes das investigações sobre a evolução psicogenética da
} 
aquisição da língua escrita foram consideradas, pelas próprias autoras, uma revolução conceitual (LUCAS, 2009, p. 98).

Após a publicação dos estudos de Ferreiro e Teberosky (1985), em escolas brasileiras, houve tentativas de implementação de práticas pedagógicas alfabetizadoras tendo como base os postulados das pesquisas por elas realizadas. Muitas vezes, a não apropriação dos complexos postulados desse referencial por estudiosos da área e por equipes pedagógicas de redes de ensino responsáveis pela formação continuada em serviço fizeram com que chegassem aos professores, quer sejam do ensino fundamental, quer sejam da educação infantil, equívocos teóricos que geraram falsas inferências. Com base em reflexões apresentadas por Azenha (2006) Lucas (2009) realizou uma síntese da má apropriação dos postulados de Ferreiro e Teberosky sobre o processo de alfabetização, com o intuito de depreender deles orientações teórico-metodológicas:

- utilizar em sala de aula as situações de entrevistas semelhantes às utilizadas por Ferreiro e Teberosky para coleta de dados, acreditando que essas situações eram de aprendizagem;

- interpretar os níveis de apropriação da língua escrita como elemento para definir pré-requisitos de identificação de prontidão para a aprendizagem da leitura e da escrita;

- utilizar os níveis de apropriação da escrita como critério para formação de classes homogêneas;

- organizar ambientes alfabetizadores, creditando a esse cenário parte da responsabilidade pela aprendizagem da leitura e escrita pela criança;

- criar sequências didáticas ou programas de ensino, pautando-se na sucessão dos níveis evolutivos da aprendizagem da linguagem escrita;

- acreditar que a valorização da escrita espontânea do aluno e de um ambiente rico e estimulante em escrita limita a intervenção do professor (LUCAS, 2009, p. 101).

\subsection{Principais contribuições da Teoria Histórico-Cultural}

Vygotski (2000) e Luria (2006) são os representantes da THC que pesquisaram, de forma mais evidente, questões que envolvem a aprendizagem da escrita. Ambos a consideram um instrumento cultural complexo e reconhecem que sua aprendizagem "[...] começa muito antes da primeira vez em que o professor coloca um lápis em sua mão [da criança] e lhe mostra como formar letras" (LURIA, 2006, p. 143).

Para Vygotski (2000), a escrita não deve ser apresentada como um ato mecânico ou simplesmente uma habilidade técnica, já que é uma complexa atividade cultural que precisa ser apropriada e compreendida em seus usos sociais. Quando se enfatiza apenas o reconhecimento de traços e sinais, atrelado aos aspectos psicomotores, não se ensina a escrita e obscurece-se a verdadeira função que essa aprendizagem desempenha no desenvolvimento 
LUCAS, Maria Angélica Olivo Francisco; SAITO, Heloisa Toshie Irie; LAZARETTI, Lucinéia Maria. Reflexões sobre o ensino da língua escrita em tempos de ampliação da escolarização obrigatória.

cultural da criança. De acordo com Vygotski (2000, p. 184), devemos conceber a escrita como “[...] um sistema especial de símbolos e signos cujo domínio significa um ponto crítico em todo o desenvolvimento cultural da criança”. Leontiev (1978), por sua vez, explica que a linguagem, cuja origem vincula-se às necessidades historicamente produzidas, apresenta-se na particularidade da criança como necessidade de comunicação com o outro, de apropriação da experiência histórico-cultural e de aquisição de instrumentos para o pensamento, subsumidas a condições concretas e objetivas que permitam esse processo. Isso significa que o domínio da leitura e da escrita pela criança permite a sua participação ativa da vida social; indica, ainda, que o relacionamento da criança com os conhecimentos sistematizados provoca transformações qualitativas no seu psiquismo.

De acordo com pressupostos defendidos por representantes da THC, a aprendizagem da escrita é extremamente complexa, pelo fato de ser uma representação de segunda ordem "[...] pois consiste em uma representação de segunda ordem, ou seja, é constituída por um sistema de signos que representam os sons e as palavras da linguagem oral, os quais, por sua vez, representam objetos, ações, fenômenos reais" (LUCAS, 2009, p. 103).

Da explicação acima deriva a relevância de, como profissionais e pesquisadores acerca da educação infantil, conhecermos o processo histórico da aprendizagem da escrita que se apresenta de das seguintes formas ao longo do desenvolvimento da criança: por meio do gesto, da brincadeira e do desenho. O aspecto comum dessas atividades é que elas compartilham a função

simbólica, sendo, portanto, representações de algo (VYGOTSKI, 2000). Então, se elas "contribuem para o desenvolvimento da capacidade de representar simbolicamente, consequentemente, contribuem para o processo de aquisição da escrita como sistema de representação de segunda ordem" (LUCAS, 2009, p. 104-105).

Vigotski afirma que a história da aprendizagem da escrita pode ser explicada desde os primeiros meses do bebê, quando, na ausência da linguagem oral e com a intenção de obter ou indicar algum objeto, manifesta sua necessidade por meio de gestos que passam a simbolizar, visualmente, algum objeto ou pessoa, que indicam, apontam e, portanto, comunicam algo. Trata-se de uma escrita feita no ar, diz Vygotski (2000). Nessa história, as brincadeiras e os desenhos vão ligar os gestos à escrita.

Nesse intenso processo de aprendizagem na primeira infância, emerge a brincadeira de papéis, que tem como principal característica a capacidade de a criança substituir um objeto real por um lúdico. Essa substituição de um objeto por outro faz com que um se torne signo 
LUCAS, Maria Angélica Olivo Francisco; SAITO, Heloisa Toshie Irie; LAZARETTI, Lucinéia Maria. Reflexões sobre o ensino da língua escrita em tempos de ampliação da escolarização obrigatória.

do outro. Na brincadeira de papéis, para o desenvolvimento da capacidade de simbolizar, não é imperioso que haja semelhanças entre o objeto real e o simbolizado, mas que seja possível realizar um gesto representativo com o objeto real. Assim, uma trouxa de tecido pode se converter em um bebê por permitir fazer com ela os gestos característicos de alimentar, de acalentar e de cuidar de um bebê. Essa substituição de objetos reais por objetos lúdicos ou imaginários tem implicações qualitativas no psiquismo infantil e na formação do pensamento, complexificando as operações mentais. A brincadeira de papéis contribui para o desenvolvimento das funções psíquicas e para o autodomínio da conduta, como principal nova formação no período pré-escolar, e para os processos simbólicos do pensamento (LAZARETTI, 2016). Isso demonstra que a criança, ao representar simbolicamente na brincadeira, faz importantes conquistas que miram em direção à escrita, pois essa também é uma forma de representação. De acordo com Vygotski (2000, p. 191): “[...] a representação simbólica no jogo é essencialmente uma forma particular de linguagem num estágio precoce que leva diretamente à linguagem escrita".

O mesmo ocorre com o desenho, considerado por Vygotski (2000) uma linguagem escrita peculiar. A criança terá consciência do significado simbólico do desenho quando a fala se tornar habitual. Nesse sentido, demonstrará em suas produções gráficas o que conhece, falando sobre ele como se estivesse narrando uma história. Isso quer dizer que "[...] o desenho é uma linguagem gráfica nascida da linguagem verbal” (VYGOTSKI, 2000, p. 192). Contudo, nesse momento, o desenho ainda é um simbolismo de primeiro grau, ou seja, representa os objetos e não as palavras.

No processo de desenvolvimento do desenho infantil, há um momento no qual a criança realiza marcas no papel que representam algo. Luria (2006) observou essa fase por meio de experimentos nos quais solicitava que crianças representassem simbolicamente algumas frases para não as esquecer. Ele descreveu como elas responderam a essa complexa tarefa e observou estágios de desenvolvimento da escrita, bem como os fatores que as habilitavam a passar de um nível ao outro, explicitando que "[...] do momento em que uma criança começa, pela primeira vez, a aprender a escrever até a hora em que finalmente domina essa habilidade há um longo período" (LURIA, 2006, p. 180).

Os estágios observados por Luria foram estudados por Azenha (2006) que assim os organizou: escrita imitativa - as crianças imitavam a escrita em sua aparência, geralmente cursiva e em forma de zigue-zague, não desempenhando função mnemônica; escrita topográfica - as crianças produziam rabiscos que serviam como recursos úteis à memorização 
LUCAS, Maria Angélica Olivo Francisco; SAITO, Heloisa Toshie Irie; LAZARETTI, Lucinéia Maria. Reflexões sobre o ensino da língua escrita em tempos de ampliação da escolarização obrigatória.

das frases ditadas porque eram anotados de forma diferenciada no espaço do papel; escrita pictográfica - após variar o conteúdo das frases ditadas, introduzindo atributos de cor, tamanho, forma e quantidade, as crianças utilizavam signos (semelhantes a pequenos desenhos) para registrá-las os quais forneciam indicativos do conteúdo de suas anotações; escrita simbólica - as crianças deixam de utilizar signos figurativos e incluem signos arbitrários em seus registros, criando técnicas para diferenciá-los tendo em vista a memorização das frases ditadas.

Além de considerarmos esse processo, é importante reconhecermos que a escrita comunica e transmite ideias, pensamentos e conhecimentos por meio de palavras. O domínio da palavra, que ocorre primeiro no âmbito oral, é a célula nuclear do ensino da língua escrita, uma vez representa a unidade entre pensamento e linguagem; porém, não é a palavra em si, mas a rede de significações que a eleva à condição de conceito e de generalização.

\begin{abstract}
O significado da palavra só é um fenômeno de pensamento na medida em que o pensamento está relacionado à palavra e nela se materializado, e vice-versa: é um fenômeno de discurso apenas na medida em que o discurso está vinculado ao pensamento e focalizado por sua luz. É um fenômeno do pensamento discursivo ou da palavra consciente, é a unidade da palavra com o pensamento (VIGOTSKII, 2001, p. 398).
\end{abstract}

Das assertivas expostas derivam orientações teórico-metodológicas favoráveis ao campo da educação infantil, as quais sinteticamente destacamos:

a) em de situações didáticas planejadas e intencionais, deve-se privilegiar a proposição de ações que envolvam o desenho e a brincadeira de papéis em diferentes espaços e em distintas situações no cotidiano escolar, propiciando, dessa forma, à criança, o desenvolvimento da sua capacidade de simbolizar e a aprendizagem da língua escrita;

b) a organização do ensino na educação infantil deve primar por ações que mobilizem interesses e necessidades nas crianças para o mundo da leitura e da escrita, em seus usos sociais; ações que representem as complexas atividades culturais da humanidade sem se restringir a realização de atividades que visem apenas o desenvolvimento de habilidades mecânicas, repetitivas e sem sentido para os aprendizes;

c) quando incorporadas aos seus usos sociais, a escrita adquire significado para as crianças, criando motivos para aprendê-la;

d) o caráter lúdico deve prevalecer nas ações que envolvem o processo de ensino e aprendizagem da escrita.

Enfim, do mesmo modo como as crianças se apropriam da linguagem oral tendo em vista a necessidade de se comunicar e interagir com os outros, a escrita precisa se tornar uma necessidade para elas, que vivem em uma sociedade grafocêntrica. Nesse sentido, 
LUCAS, Maria Angélica Olivo Francisco; SAITO, Heloisa Toshie Irie; LAZARETTI, Lucinéia Maria. Reflexões sobre o ensino da língua escrita em tempos de ampliação da escolarização obrigatória.

implementar os processos de alfabetização e letramento significa promover de forma intencional e sistemática a interação das crianças com essas formas de linguagem, enriquecendo suas vivências, tal como exporemos a seguir.

Respaldando-nos em Soares (1998), concebemos a alfabetização como um processo de aprendizagem de habilidades necessárias aos atos de ler e escrever e o letramento como o estado ou a condição do sujeito que incorpora práticas sociais de leitura e escrita. No Brasil, o termo letramento foi cunhado na segunda metade da década de 1980 como uma tradução do vocábulo inglês literacy. $\mathrm{O}$ intuito era ampliar o conceito de alfabetização, demonstrando que a aprendizagem e o uso da língua escrita influenciam tanto o grupo social que a utiliza, quanto o indivíduo que aprende a usá-la nos âmbitos sociais, culturais, políticos, econômicos, cognitivos e linguísticos (MORTATTI, 2004). Destarte, os termos alfabetização e letramento não são sinônimos. Trata-se de dois processos diferentes que, contudo, ocorrem de forma indissociável e interdependente:

[...] a alfabetização se desenvolve no contexto de e por meio de práticas sociais de leitura e de escrita, isto é, através de atividades de letramento, e este, por sua vez, só pode desenvolver-se no contexto da e por meio da aprendizagem das relações fonema-grafema, isto é, em dependência da alfabetização (SOARES, 2004a, p. 14).

No processo de ensino e aprendizagem da língua escrita deve haver, portanto, um equilíbrio entre as ações específicas de alfabetização e as que intentam aproximar as crianças das práticas sociais que abarcam as habilidades de leitura e escrita. Isso significa, conforme Soares (2004a), que há uma relação de complementaridade entre ambos os processos, sendo um erro dissociá-los porque

[...] a entrada da criança [...] no mundo da escrita se dá simultaneamente por esses dois processos: pela aquisição do sistema convencional de escrita - a alfabetização e pelo desenvolvimento de habilidades de uso desse sistema em atividades de leitura e escrita, nas práticas sociais que envolvem a língua escrita - o letramento (SOARES, 2004a, p. 14).

Essa forma de compreender a relação entre alfabetização e letramento é relevante, pois tais processos possuem diferentes facetas cujas distintas naturezas solicitam procedimentos de ensino distintos. Para algumas facetas, não há como abrir mão de metodologias dotadas de intencionalidade e sistematização, como é o caso da consciência fonológica e da identificação das relações fonema-grafema - habilidades necessárias para a aprendizagem do sistema de escrita. Nessas situações, é imprescindível a presença do professor organizando o ensino com objetivos claros e definidos. Para outras facetas, além de intencionais e sistematizadas, é possível recorrer a metodologias indiretas, subordinadas às possibilidades e motivações das 
crianças. É o caso de situações nas quais para imergi-las no mundo da escrita, promovem-se experiências variadas com a leitura e a escrita, conhecem-se diferentes tipos e gêneros de material escrito, interagindo-se com eles.

Vejamos um exemplo apresentado por Soares (2004b, p. 7-8), em entrevista concedida à Revista Caderno do Professor:

\begin{abstract}
Brincadeiras e jogos que envolvem a língua escrita, poemas, histórias da literatura infantil são práticas de letramento a partir das quais devem ser desenvolvidas as atividades que visem à consciência fonológica, às relações oralidade-escrita, às equivalências fonemas-grafemas, ao reconhecimento de palavras escritas. Por exemplo: a professora lê uma história, chamando a atenção para o título, mostrando o texto, identificando personagens, pedindo inferências ao longo da leitura, discute a história com as crianças, pede que a recontem, faz perguntas de interpretação - até aqui estamos falando de atividades de letramento; em seguida, pode destacar uma ou algumas palavras-chave da história, que servirão de base para atividades de consciência fonológica, de identificação de sílabas, de relações fonemas-grafemas, etc. - enfim, atividades de alfabetização, que estarão assim contextualizadas em práticas reais de leitura e de escrita.
\end{abstract}

Em resumo, trata-se de alfabetizar letrando e letrar alfabetizando. Compreender os conceitos de alfabetização e de letramento, reconhecendo-os como indissociáveis e interdependentes é necessário, sobretudo nos dias atuais, quando se averigua, além da confusão conceitual entre ambos os processos, a perda da clareza e da intencionalidade na prática docente que os envolvem, bem como a crítica à antecipação da escolarização.

\title{
3 Práticas pedagógicas de alfabetização e de letramento na educação infantil
}

Os apontamentos expostos até aqui, advindos da perspectiva construtivista de alfabetização, da THC e das discussões acerca da relação entre os processos de alfabetização e de letramento, indicam a importância de implementarmos situações didáticas que enriqueçam as experiências que envolvem a escrita na educação infantil e promovam a sua aprendizagem, de modo que as crianças percebam que essa linguagem é necessárias para si e para a vida em grupo.

Para pensarmos práticas pedagógicas voltadas para a aprendizagem da escrita, destacamos algumas orientações teórico-metodológicas que abarcam os processos de alfabetização e de letramento presentes em dois documentos oficiais, um de âmbito estadual e outro de âmbito nacional.

Em Orientações pedagógicas da educação infantil: estudos e reflexões para a organização do trabalho pedagógico (PARANÁ, 2015), há a indicação de ações relativas à brincadeira, ao desenho, à narração de histórias e ao trabalho com o nome próprio. Nesse 
LUCAS, Maria Angélica Olivo Francisco; SAITO, Heloisa Toshie Irie; LAZARETTI, Lucinéia Maria. Reflexões sobre o ensino da língua escrita em tempos de ampliação da escolarização obrigatória.

documento é comentado que, ao brincar de faz de conta, a criança representa simbolicamente, desenvolvendo uma das funções necessárias à aprendizagem da escrita - a função simbólica e reflete sobre o papel social da linguagem nas mais variadas situações sociais.

Em relação ao desenho, o referido documento assevera que não se trata de ilustração para a criança colorir, mas de representação gráfica elaborada por ela, seja para brincar, seja para expressar-se livremente, seja para registrar algo. Tais registros gráficos tornam-se símbolos auxiliares à memória e contêm os rudimentos da escrita. Nesse processo, a criança precisa compreender que, além de desenhar os objetos, as pessoas e os fenômenos, podemos também, parafraseando Vygotski (2000), “desenhar” a fala, ou seja, escrever.

A narração de histórias é apontada como uma importante ação pedagógica, pois, ao escutarem uma história, as crianças, desde muito pequenas, interagem com o discurso escrito. Por essa razão, compete ao professor incorporar essa ação à sua prática pedagógica, planejá-la e ler para as crianças textos de boa qualidade, pois o contato da criança com a escrita é imprescindível para a promoção dos processos de letramento e de alfabetização.

$\mathrm{O}$ documento analisado também destaca que o reconhecimento ou o registro do nome próprio é uma forma de antecipar situações possíveis somente após a apropriação da escrita e que, por isso, sugerir situações de leitura e de escrita do nome próprio é uma forma de atuarmos na zona de desenvolvimento proximal das crianças.

No âmbito nacional, em 2016, o MEC publicou a coleção intitulada Leitura e escrita na educação infantil ${ }^{1}$, objetivando contribuir com a formação de professores. Nesse documento, há a defesa da linguagem como "[...] produto e produção humana, como meio e modo de interação, da qual as crianças intensamente participam” (BRASIL, 2016, p. 81). Os autores exemplificam com cenas cotidianas que ocorrem no espaço da educação infantil, demonstrando como a oralidade, a escrita e a leitura estão presentes em todos os momentos do dia a dia e como podemos explorá-las no sentido de promover o desenvolvimento cultural da criança.

Tal desenvolvimento, via instituição educativa, somente se efetiva, mediante práticas intencionais e sistematizadas. Nesse sentido, ressaltamos a relevância do planejamento para o professor pensar em encaminhamentos metodológicos que ampliem o interesse das crianças pela escrita e promovam a sua aprendizagem, de modo a possibilitar-lhes a compreensão do

\footnotetext{
${ }^{1}$ Essa coleção é constituída de oito cadernos compostos por três unidades temáticas cada um, mais um caderno de apresentação e um encarte destinado às famílias das crianças. Para a elaboração deste texto, optamos por trazer questões apresentadas no Caderno 3, na Unidade 3, denominada Criança, linguagem oral e linguagem escrita: modos de apropriação.
} 
LUCAS, Maria Angélica Olivo Francisco; SAITO, Heloisa Toshie Irie; LAZARETTI, Lucinéia Maria. Reflexões sobre o ensino da língua escrita em tempos de ampliação da escolarização obrigatória.

emprego de tal linguagem nas mais variadas práticas cotidianas e de recorrer a essa forma de linguagem para interagir com os demais, para registrar um fato ocorrido, para guardar lembranças. De acordo com Smolka, Magiolino e Rocha (2016, p. 106, grifo das autoras):

Somente com a sistematicidade do trabalho da professora, incorporando o calendário nas práticas cotidianas, propondo a 'leitura' das imagens e convidando as crianças a 'escreverem' suas vivências com figuras e desenhos todos os dias, é que se tornam possíveis novos modos de compreensão e de uso dessa forma de registro cultural do tempo. Nesse processo, torna-se possível, também, a produção e a partilha de novas significações.

Assim, é no contato diário por meio de ações sistematizadas e intencionais com a escrita que possibilitam reflexões e apropriações diversas sobre o seu funcionamento, que as crianças, gradativamente, adquirem competência linguística para compreenderem o uso dessa forma de linguagem nas diversas situações cotidianas, tendo o professor como exemplo de sujeito leitor e escritor.

As crianças vão imitando a leitura, memorizando o texto, reconhecendo e relacionando as palavras escritas, apropriando-se do produto de sua própria experiência. [...] As crianças começam a imitar também a escrita, a copiar, a esboçar o traçado convencional das letras, a perguntar sobre elas; querem saber sempre mais (SMOLKA; MAGIOLINO; ROCHA, 2016, p. 108).

Isso nos mostra o importante papel da educação infantil, tendo em vista a formação humana, pois as práticas nesse nível de ensino podem possibilitar à criança o contato com tudo aquilo que a humanidade constituiu ao longo de sua história, como também podem leválas à compreensão de vários conceitos se, para tanto, forem implementadas ações propositivas e qualitativas. Vale ressaltar que essas ações devem considerar as características infantis e o desenvolvimento das crianças, tendo como princípios de organização da prática pedagógica a ludicidade e a sistematicidade. Em outras palavras, se as diferentes propostas pedagógicas para a educação infantil forem planejadas, ricas de ludicidade e voltadas para o atendimento das especificidades das crianças, certamente, colaborarão para os processos de alfabetização e de letramento. Sobre essa questão, Saito e Oliveira (2018, p. 13) argumentam:

[...] reforçamos a crença do trabalho docente na educação infantil para a aprendizagem e o desenvolvimento da criança com ações objetivadas e intencionalmente esclarecidas, uma vez que influenciam diretamente na promoção da compreensão humana do sujeito infantil. Isso somente ocorrerá se as ações propostas forem de qualidade e tiverem intencionalidade, almejando constantemente pela emancipação do indivíduo. Por isso, defendemos uma educação infantil lúdica, alegre, colorida e participativa, que acolha as crianças em sua plenitude e que as permita viver e conhecer o mundo, as pessoas, o saber elaborado pela humanidade ao longo do tempo histórico, enfim, conhecer tudo aquilo que traga aprendizagens e desenvolvimento. 
LUCAS, Maria Angélica Olivo Francisco; SAITO, Heloisa Toshie Irie; LAZARETTI, Lucinéia Maria. Reflexões sobre o ensino da língua escrita em tempos de ampliação da escolarização obrigatória.

Em harmonia com os documentos acima citados e com a proposta que defendemos para a educação infantil no que se refere aos processos de alfabetização e de letramento, sugerimos alguns recursos e orientações como, por exemplo, o trabalho com literatura infantil de boa qualidade; a realização de atividades com jogos e desenhos; a proposição de escrita que tenha significado para as crianças, por meio de diferentes gêneros textuais, tendo o professor como escriba; a implementação de atividades diversas que permitam a reflexão acerca da escrita, bem como de sua função social.

Vale ressaltar que as diferentes ações que envolvem a escrita devem ser organizadas, considerando-se a rotina peculiar da educação infantil. Nesse sentido, entendemos que a escrita deve se fazer presente em todos os momentos da prática pedagógica, desde a recepção das crianças até o momento do retorno delas aos seus lares; não apenas em situações pontuais ou em alguns momentos da rotina nos quais o professor considera oportuno enfatizar essa forma de linguagem.

\section{Considerações finais}

Mediante as reflexões apresentadas no decorrer do texto, concluímos que podemos e devemos propiciar um trabalho qualitativo com a escrita nos diferentes momentos e espaços da educação infantil, possibilitando a participação das crianças em situações sistematizadas que as façam pensar acerca da funcionalidade dessa linguagem.

O trabalho qualitativo que defendemos refere-se a uma prática pedagógica planejada que acolha as crianças em suas necessidades e que as permita se constituírem como sujeitos participantes de uma sociedade, empregando, nas mais variadas situações, a escrita para interagirem entre si. Em outras palavras, tal trabalho consiste em ações com e para as crianças, ações que objetivam a formação humana, tornando-as participativas e autônomas nas diferentes tramas sociais.

Esse trabalho pode e deve ocorrer nas mais variadas situações da rotina da educação infantil e não somente em horários específicos e reservados para atividades que envolvem aspectos da escrita, ou seja, pode ser estendido aos mais variados momentos, como o da acolhida, o do sono, o do parque, o da alimentação, o da higienização e o da formação da fila. Isso significa que, ao longo do dia, há infinitas possibilidades de, na educação infantil, ser promovida a aprendizagem da escrita, desde que os encaminhamentos metodológicos sejam pensados e organizados para tal fim. 
LUCAS, Maria Angélica Olivo Francisco; SAITO, Heloisa Toshie Irie; LAZARETTI, Lucinéia Maria. Reflexões sobre o ensino da língua escrita em tempos de ampliação da escolarização obrigatória.

Nesse sentido, o papel do professor é relevante, pois é ele quem organiza o trabalho efetivo com a língua escrita e faz as diferentes mediações para que haja a apropriação de conhecimentos pela criança. Para isso, o professor necessita compreender os processos de aprendizagem e de desenvolvimento da escrita, como também ser um usuário exemplar da escrita para as crianças o terem como máxima referência (SAITO; LUCAS; MIRANDA, 2016).

É importante pontuar que, embora tenhamos garantidos na legislação nacional alguns direitos para as crianças e para os profissionais da educação infantil, as estratégias governamentais tomadas para o atendimento de um maior número de crianças nesse nível de ensino foram na direção de alocar as crianças da pré-escola em espaços do ensino fundamental. Isso, na prática, significou a inserção antecipada da criança pequena em um universo que não combina com as ações necessárias à educação infantil, ou seja, significou a antecipação da exigência da aprendizagem da escrita formal pela criança. Por esse motivo, justificamos a necessidade de refletirmos sobre a especificidade do trabalho com a língua escrita na educação infantil, para não nos perdermos em um cenário que inviabiliza sua aprendizagem de uma maneira lúdica e compreensiva e possamos ir ao encontro de práticas pedagógicas que realmente se constituam práticas de alfabetização e de letramento na educação infantil.

\section{Referências}

AZENHA, M. G. Imagens e letras - Ferreiro e Luria: duas teorias psicogenéticas. São Paulo: Ática, 2006.

BARBOSA, J. J. Alfabetização e leitura. 2. ed. São Paulo: Cortez, 1994. (Série formação do professor, v. 16).

BRASIL. Lei n. ${ }^{\circ}$ 8.069, de 13 julho de 1990. Dispõe sobre o Estatuto da Criança e do Adolescente, e dá outras providências. Diário Oficial da União, Brasília, 16 jul. 1990. Disponível em: http://www2.camara.leg.br/legin/fed/lei/1990/lei-8069-13-julho-1990-372211-publicacaooriginal-1pl.html. Acesso em: 17 dez. 2018.

BRASIL. Lei n. ${ }^{\circ}$ 9.394, de 20 de dezembro de 1996. Estabelece as diretrizes e bases da educação nacional. Diário Oficial da União, Brasília, 23 dez. 1996. Disponível em:

http://www.planalto.gov.br/ccivil_03/LEIS/L9394.htm. Acesso em: 18 dez. 2018.

BRASIL. Ministério da Educação e do Desporto. Secretaria de Educação Fundamental. Referencial curricular nacional para a educação infantil. Brasília: MEC/SEF, 1998. Disponível em: http://portal.mec.gov.br/seb/arquivos/pdf/rcnei_vol1.pdf. Acesso em: 18 dez. 2018.

BRASIL. Resolução CEB n. ${ }^{\circ}$ 1, de 7 de abril de 1999. Institui as Diretrizes Curriculares Nacionais para a Educação Infantil. Diário Oficial da União, Brasília, 13 abr. 1999. Disponível em: http://portal.mec.gov.br/cne/arquivos/pdf/CEB0199.pdf. Acesso em: 18 dez. 2018. 
LUCAS, Maria Angélica Olivo Francisco; SAITO, Heloisa Toshie Irie; LAZARETTI, Lucinéia Maria. Reflexões sobre o ensino da língua escrita em tempos de ampliação da escolarização obrigatória.

BRASIL. Lei n..$^{\circ} 11.114$, de 16 de maio de 2005. Altera os arts. $6^{\circ}, 30,32$ e 87 da Lei n. ${ }^{\circ} 9.394$, de 20 de dezembro de 1996, com objetivo de tornar obrigatório o início do ensino fundamental aos seis anos de idade. Diário Oficial da União, Brasília, 17 maio 2005. Disponível em:

http://www.planalto.gov.br/ccivil_03/_Ato2004-2006/2005/Lei/L11114.htm. Acesso em: 18 dez. 2018.

BRASIL. Lei n. ${ }^{\circ} 11.274$, de 6 de fevereiro de 2006. Altera a redação dos arts. 29, 30, 32 e 87 da Lei $\mathrm{n}^{\mathrm{o}}$ 9.394, de 20 de dezembro de 1996, que estabelece as diretrizes e bases da educação nacional, dispondo sobre a duração de 9 (nove) anos para o ensino fundamental, com matrícula obrigatória a partir dos 6 (seis) anos de idade. Diário Oficial da União, Brasília, 7 fev. 2006. Disponível em: http://www.planalto.gov.br/ccivil_03/_Ato2004-2006/2006/Lei/L11274.htm. Acesso em: 18 dez. 2018.

BRASIL. Lei n. ${ }^{\circ}$ 12.796, de 4 de abril de 2013. Altera a Lei no 9.394, de 20 de dezembro de 1996, que estabelece as diretrizes e bases da educação nacional, para dispor sobre a formação dos profissionais da educação e dar outras providências. Diário Oficial da União, Brasília, DF, 5 abr. 2013. Disponível em: http://www.planalto.gov.br/ccivil_03/_ato2011-2014/2013/lei/112796.htm. Acesso em: 18 dez. 2018.

BRASIL. Ministério da Educação. Secretaria da Educação Básica. Linguagem oral e linguagem escrita na educação infantil: práticas e interações. Brasília: MEC/SEB, 2016. Disponível em: http://www.projetoleituraescrita.com.br/wp-content/uploads/2017/08/Caderno_3.pdf. Acesso em: 17 dez. 2018.

CZYZEWSKI, A.; LUCAS, M. A. O. F. A organização dos espaços educativos no processo de ampliação do ensino fundamental. In: FERREIRA,V. S; GESSER,V. (org.). Ensino fundamental de nove anos: princípios, pesquisas e reflexões. Curitiba: CRV, 2013. p. 131-150.

COLELLO, S. M. G.; LUCAS, M. A. O. F. Lengua escrita em la educación infantil: caminos del apredizaje y enseñanza. Revista Internacional D'Humanitats, São Paulo/Barcelona, v. 44, p. 15-24, set./dez. 2018.

FERREIRO, E.; TEBEROSKY, A. Psicogênese da língua escrita. Porto Alegre: Artes Médicas, 1985.

LAZARETTI, L. M. Idade pré-escolar (3-6 anos) e a educação infantil: a brincadeira de papéis sociais e o ensino sistematizado. In: MARTINS, L. M. (org.). Periodização histórico-cultural do desenvolvimento psíquico: do nascimento à velhice. Campinas: Autores Associados, 2016. p. 129148.

LEONTIEV, A. N. O desenvolvimento do psiquismo. Lisboa: Livros Horizonte, 1978.

LUCAS, M. A. O. F. Os processos de alfabetização e letramento na educação infantil:

contribuições teóricas e concepções de professores. 2008. 322 f. Tese. (Doutorado) - Programa de Pós-Graduação da Faculdade de Educação, Universidade de São Paulo, São Paulo, 2009.

LUCAS, M. A. O. F.; MACHADO, M. C. G. Percalços da educação infantil como direito da criança: análise da história e da legislação das décadas de 1980 e 1990. Práxis Educativa, Ponta Grossa, v. 7 , n. 1, p. 107-128, jan./jun. 2012. Disponível em:

https://www.revistas2.uepg.br/index.php/praxiseducativa/article/view/2963. Acesso em: 17 dez. 2018.

LURIA, A. R. O desenvolvimento da escrita na criança. In: VYGOTSKY, L. S.; LURIA, A. R.; LEONTIEV, A. N. Linguagem, desenvolvimento e aprendizagem. São Paulo: Ícone, 2006. p. 143189.

MELLO, M. C. O. Emília Ferreiro e a alfabetização no Brasil: um estudo sobre a psicogênese da língua escrita. São Paulo: UNESP, 2007.

MORTATTI, M. R. L. Educação e letramento. São Paulo: UNESP, 2004.

PARANÁ. Secretaria de Estado da Educação. Orientações pedagógicas da educação infantil: estudos e reflexões para a organização do trabalho pedagógico. Curitiba: SEED/PR, 2015. 
LUCAS, Maria Angélica Olivo Francisco; SAITO, Heloisa Toshie Irie; LAZARETTI, Lucinéia Maria. Reflexões sobre o ensino da língua escrita em tempos de ampliação da escolarização obrigatória.

SAITO, H. T. I.; LUCAS, M. A. O. F.; MIRANDA, M. J. C. A mediação docente no desdobramento da prática pedagógica. Linha Mestra, Campinas, v. 10, n. 30, p. 1158-1162, set./dez. 2016. Disponível em: https://linhamestra30.files.wordpress.com/2017/03/lm_16_12_f.pdf. Acesso em: 17 dez. 2018.

SAITO, H. T. I.; OLIVEIRA, M. R. F. Trabalho docente na educação infantil: olhares reflexivos para a ação intencional e planejada do ensino. Imagens da Educação, Maringá, v. 8, n. 1, p. 1-15, mar. 2018. Disponível em: http://periodicos.uem.br/ojs/index.php/ImagensEduc/article/view/39310/pdf. Acesso em: 17 dez. 2018.

SMOLKA, A. L. B.; MAGIOLINO, L. L. S.; ROCHA, M. S. P. M. L. Crianças, linguagem oral e linguagem escrita: modos de apropriação. In: BRASIL. Linguagem oral e linguagem escrita na educação infantil: práticas e interações. Brasília: MEC/SEB, 2016. p. 81-118. Disponível em: http://www.projetoleituraescrita.com.br/wp-content/uploads/2017/08/Caderno_3.pdf. Acesso em: 17 dez. 2018.

SOARES, M. B. Letramento: um tema em três gêneros. Belo Horizonte: Autêntica, 1998.

SOARES, M. B. Alfabetização e letramento. São Paulo: Contexto, 2004a.

SOARES, M. B. Alfabetização e letramento. Caderno do professor, Belo Horizonte, n. 12, p. 6-11, dez. 2004b.

VIGOTSKII, L. S. Aprendizagem e desenvolvimento intelectual na idade escolar. In: VIGOTSKII, L. S.; LURIA, A. R.; LEONTIEV, A. N. Linguagem, desenvolvimento e aprendizagem. São Paulo: Ícone, 2001. p. 103-119.

VYGOTSKI, L. S. La prehistoria del desarollo del lenguaje intelectual da criança. In: VYGOTSKI, L. S. Obras escogidas. Madrid: Centro de Publicaciones del M.E.C. y Visor Distribuiciones, 2000. T. III, p. 183-206.

WEISZ, T. Apresentação. In: FERREIRO, E.; TEBEROSKY, A. Psicogênese da língua escrita. Porto Alegre: Artes Médicas, 1999. p. vii-ix. 